\title{
Editorial
}

Community

Community Genet 2007;10:1

DOI: $10.1159 / 000096273$

\section{From Milestone to Moral Obligation}

\author{
Leo ten Kate \\ Department of Clinical Genetics and Human Genetics, VU University Medical Center, Amsterdam, The Netherlands
}

This first issue of the 2007 volume 10 of Community Genetics represents a milestone in several ways. First, its appearance shows that we have succeeded in filling the empty niche for publications at the crossing of medicine, genetics and society. What started as an experiment with unsure outcome has turned into a secure provision. Second, its early appearance indicates that we have a well-filled portfolio of accepted manuscripts awaiting publication. This has been different in the past, when at times we were not sure if and when the next issue would appear. Issues 3 and 4 of the 2000 volume for instance did not appear before April and May 2001. Notwithstanding such problems, we have always stuck to maintaining a high quality of papers. About $50 \%$ of submissions never made it to appearance. This, of course, is only possible by the voluntary effort of the many peer reviewers which we gratefully acknowledge. Third, this year (2007), the first impact factor for the journal will become available. This will be based on the sum of all articles published in 2004 and 2005 as a denominator and a count of all references to these articles in 2005 and 2006 as numerator.

Looking back to the preceding volumes, it is quite clear that spontaneous submissions of original research papers published in regular issues are the backbone of the journal. This is not to disqualify special issues, reviews, case reports or other sections we have. A backbone without head, limbs or tail would not be attractive. However, here, I want to focus on the 118 original papers which appeared in the first 9 volumes of the journal. Where did they come from and what did they report on?

All continents and 28 different countries were represented. The majority of papers came from Europe $(n=61)$, followed by the Americas (37) and Asia (13). If categorized by country, the lead was taken by the United States of America (29), followed by the United Kingdom (16) and the Netherlands (14). As to discipline, the largest group of authors (44) was composed of geneticists (of all kinds), meaning that the majority of authors were nongeneticists. Among them, epidemiologists (10) and psychologists (8) prevail, but many other different sciences are represented. Just a few examples are public health, social medicine, economics, social science and behavioral science, illustrating the multidisciplinary character of community genetics.

\section{KARGER}

Fax +41613061234 E-Mail karger@karger.ch www.karger.com
(C) 2007 S. Karger AG, Basel

$1422-2795 / 07 / 0101-0001 \$ 23.50 / 0$

Accessible online at:

www.karger.com $/ \mathrm{cmg}$
Eighty papers focused on specific conditions or groups of conditions. A quarter of these (20) concentrated on cancer, either on a specific form or more or less in general, followed by birth defects in general (10), Down syndrome (7), thalassemia and other hemoglobinopathies (7), and cystic fibrosis (4). Twenty-four other conditions were specified. The subjects of the studies in these $80 \mathrm{pa}-$ pers could be categorized into characteristics of the (patients with the) condition (35; e.g., prevalence, classification or risk factors), testing and screening (31; e.g., utilization, psychological sequels or economic evaluation), and others (14; e.g., performance of health care providers). Among the 38 papers which did not focus on a specific condition and were more general in scope, genetic education (6) and genetic services (4) were the largest subcategories.

As to the methodology of the 118 studies reported, questionnaires were frequently used (36). Other popular methods were interviews (12), descriptions of existing programs (12), molecular or other laboratory testing (10), evaluation of existing registry data (7), and focus groups (7).

Many years ago, Diane Brisson proposed to follow the evolution of the concept of community genetics through time [1]. Our small analysis of origin and content of original papers shows the breadth of this field. Of course, the limits are set by the editors who may reject papers on the basis of what they regard as the scope of the journal. But within these limits, the diversity of community genetics as a science is apparent. It is true that community genetics is not only a science, but also an art. This art may be more reflected in our case reports section, which started in 2003 and does not have enough papers for analysis yet. And remember, community genetics is not only a handy collective noun for related activities, but a moral obligation as well $[2,3]$.

\section{References}

1 Brisson D: Analysis and integration of definitions of community genetics. Community Genet 2000;3:99-101.

2 Ten Kate LP: Editorial. Community Genet 1998;1:1-2.

3 Ten Kate LP: Community genetics: a bridge between clinical genetics and public health. Community Genet 2005;8:7-11. 